\title{
FIGURILLAS ANTROPOMORFAS DE CHIAPA DE CORZO *
}

\author{
Por Thomas A. LeE, JR. \\ BYU-New World Archaeological \\ Foundation
}

Las 274 cabezas de figurillas, unas completas y otras fragmentadas, y los 965 fragmentos de cuerpo de Chiapa de Corzo, son solamente una muy pequeña parte del resultado de seis periodos de excavaciones en ese lugar por varios miembros de la BYU-New World Archaeological Foundation. Mayor información concerniente a Chiapa de Corzo se puede obtener levendo, entre otros, a Lowe y Agrinier (1960) y especialmente a Lowe (1962).

Las cabezas y algunos cuerpos de las figurillas de Chiapa de Corzo, están organizados en tres importantes niveles taxonómicos. En el primer nivel se ha hecho una división en cuatro grupos llamados Estilos, y se han usado números romanos del I al IV para indicarlos. Diremos en forma breve que un Estilo puede considerarse como incluyendo dentro de sí mismo todos aquellos especímenes en los que se producen los rasgos con las mismas bases técnicas. Esto es, para alcanzar los rasgos deseados los creadores usaron primordialmente el punteado, el modelado o la aplicación. Más tarde el molde sustituyó todas estas técnicas. Las líneas orientadoras para los tres primeros Estilos se tomaron de la clasificación de las figurillas de La Venta (1952), de Drucker.

En el segundo nivel de esta tipología, las figurillas se dividieron en tipos, y se puede observar en este nivel, que la generalización es mucho menor que en el nivel de Estilo, por el mayor número de diversificaciones que existen. Los atributos en este nivel incluyen la forma de la cara y del pelo, así como

* Traducido del inglés por la profesora Esther Sellarés S. 
los variados modos de retrato. El nombre del tipo es la palabra Chiapa seguida de una mayúscula. En el último nivel de esta tipología tripartita, las figurillas están divididas en variantes del tipo.

Las variantes se subdividen dentro del mismo tipo, sobre la base de uno o más atributos en los que participan internamente y que expresan una pequeña diferencia en relación con el tipo y con otras variantes del mismo tipo. Las variantes definidas dentro de los tipos se indican con el nombre del tipo seguido de un número. Los números se dan en secuencia en la multivariedad de tipos.

El nombre formal del tipo para las figurillas de Chiapa de Corzo, opuesto a un nombre descriptivo del tipo para los fragmentos de figurillas menos distintivos, es en primer lugar el número romano del Estilo, en segundo lugar el nombre del lugar, Chiapa; en tercero, una mayúscula que indica el tipo, y en cuarto lugar un número arábigo, en caso de ser una variante. Por ejemplo: I-Chiapa-Al.

Los tipos definidos para las clases de figurillas no se basan sobre el mismo criterio en cada caso. No se ha intentado clasificar todas las figurillas sobre la base de una, - de una serie de características, como si de este modo pudieran más fácilmente compararse. Lo que se ha intentado es un arreglo más flexible en el cual las clases de figurillas se han agrupado de acuerdo con el atributo, o atributos que a mi me parece justificar que se junten como una unidad. Algunos tipos están basados en solamente uno o dos atributos; pero la mayoría en muchos.

\section{DESCRIPCIÓN DE LOS TIPOS}

1-Chiapa-A, 10 especímenes (fig. la).

a) Cabeza de forma redonda con rasgos faciales naturalistas.

b) Cabeza y cuello con un perfil en forma de cuña.

c) Ojos de forma elipsoide con las pupilas redondas profundamente punteadas.

d) Oídos grandes y protuberantes.

e) Labios enormemente salidos hacia adelante, aplastados, en forma de pico de pato.

f) Pelo que enmarca la cara en forma de capucha. 
Fase: Dili.

Comp: La Victoria, Figurillas de la fase Conchas. (Coe 1961, fig. 54,55$)$.

La Venta, Tipos I-A-3, I-B-3a, I-B-3a-4. Idénticas (Drucker 1952).

J-Chiapa-AI, 15 especímenes (fig. $1 b$ ).

a) Rasgos faciales ejecutados más suavemente que los de I-Chiapa-A.

b) Forma facial gruesa y a menudo rectangular.

c) Pelo en forma de capucha suprimido.

d) Pupilas pequeñas, pero a menudo rebasando la cuenca del ojo.

e) Esta es la mejor evidencia de tonsura o de remoción del cuero cabelludo según patrones estéticos.

Fase: Dili.

Comp: La Venta.

I-Chiapa-A2, 14 especímenes (fig. lc).

a) Cara muy plana.

b) Poco relieve facial salvo la nariz.

c) Pelo peinado en forma de capucha muy destacada.

Fase: Dili.

Comp: La Venta.

I-Chiapa-A3, 6 especímenes (fig. Id) .

a) Supresión del pelo peinado en forma de capucha; pelo nunca alto ni espeso.

b) Dos marcas punteadas en el lóbulo superior de la oreja.

c) Pequeños rasgos espaciados.

d) Pintura roja en el pelo.

Fase: Dili.

Comp: La Venta.

I-Chiapa-A4, 4 especímenes (fig. le). 
a) Bajos rasgos faciales.

b) Pupilas cerca de la parte interna de las cuencas.

c) Pelo recogido en nudo encima de la cabeza y sujeto con un banda.

d) Punteado en forma de "u" en la parte superior del lóbulo de la oreja.

Fase: Probablemente Dili.

Comp: La Venta.

I-Chiapa-A5, 2 especímenes (fig. lf) .

a) Aspecto general grueso y pesado.

b) Carencia de cuello, con cabeza sobre los hombros.

c) Gran capucha de pelo.

d) Pelo recogido en nudo en la parte superior trasera de la cabeza.

e) Comisura de la boca hacia abajo en un gesto de enojo.

Fase: Cotorra-Dili.

Comp: La Venta.

I-Chiapa-A6, 4 especímenes (fig. $1 \mathrm{~g}$ ) .

a) Cara gorda.

b) Barbilla pequeña y puntiaguda.

c) Cabeza muy ancha de la parte delantera a la trasera.

d) La pupila izquierda no está al mismo nivel que la de la derecha, mira hacia arriba o abajo y afuera.

e) Cabeza decorada con tres cintas aplicadas en la parte superior, a igual distancia una de otra.

Fase: Probablemente Dili.

Comp: La Venta.

1-Chiapa-A7, 3 especimenes (fig. I $h$ ).

a) Cabeza puntiaguda.

b) Prominente rizo frontal.

c) Dientes dibujados con una pequeña línea de puntos en la boca. 
d) Pupilas muy separadas.

e) Una pequeña ranura cerca de las cuencas las separa del resto de la cara.

Fase: Dili.

Comp: La Venta.

I-Chiapa-AS, 3 especímenes (fig. li) .

a) Figuras casi completas, probablemente de infantes.

b) Todos estaban en los brazos de una persona de mayor tamaño.

c) Cara trabajada con poco cuidado, con exagerado prognatismo.

d) Labio superior echado hacia atrás contra la nariz, en dos especimenes.

e) Prenda de vestir blanca con pintura roja.

Fase: Probablemente Dili.

Comp: La Venta.

1-Chiapa-A9, 17 especímenes (fig. 1j) .

a) Cara grande y muy pesada.

b) Mejillas carnosas, barbilla reducida.

c) Boca generalmente con las comisuras hacia abajo, en gesto de enojo.

d) Muchos especímenes son más bien huecos que macizos.

Fase: Dili-Francesa.

Comp: La Venta.

I-Chiapa- $B, 5$ especímenes (fig. $2 a$ ).

a) Cabeza larga deformada, en forma de barril.

b) Labio inferior muy prominente.

c) Frontal grande.

d) Barbilla poco pronunciada, a veces hacia atrás.

e) Pelo tonsurado en el rizo frontal, a menudo con largas caídas de pelo en ambos lados.

f) Aparece una prenda de vestir roja o blanca. 
Fase: Escalera-Francesa.

Comp: Tipo parecido al Morelos de Weiant (1943, Pl. 20, 21) en Tres Zapotes. Tipo de deformación craneana que ocurre en figurillas de jade en La Venta (Drucker 1952, Pl. 46-50, Drucker, Heizer and Squire 1959, Pl. 30-36).

1-Chiapa-Bl, 5 especímenes (fig. 2b) .
a) Cabeza pequeña.
b) Prognatismo labial.
c) Mejillas carnosas y gordas.
d) Frente estrecha, unida con la nariz, boca y barbilla.

Fase: Guanacaste.

Comp: Sorprendentemente similar al tipo arcaico olmeca de Weiant, conocido como "Baby Face" de Tres Zapotes (1943, P1. 18, 19). Piña Chan (1958, 2a. parte, Láms. 13, 14) ilustra dos ejemplos que muestran relación muy estrecha con este tipo.

I-Chiapa-B-2, 3 especimenes (fig. 2c).

a) Cara redonda y gruesa.

b) Rasgos faciales profundamente trabajados, pero ocupando poco espacio en el área facial.

c) Barbilla poco destacada.

Fase: Jiquipilas.

Comp: Desconocida.

J-Chiapa-C, 4 especimenes (fig. 2d).

a) Forma facial ovalada.

b) Boca abierta.

c) Pelo dividido a la mitad, en dos partes.

d) Cabeza doblada hacia atrás al nivel del ojo, haciendo cóncava la parte trasera de la cabeza.

Fase: Francesa-Istmo.

Comp: Desconocida.

1.Chiapa-C-1, l espécimen (fig. $2 e$ ) . 
a) Naturalista.

b) Detalles muy finos.

c) Pelo recogido en forma de cono sobre la cabeza y casi invisible debajo de un complicado peinado en forma de turbante.

Fase: Dili.

Comp: Desconocida.

I-Chiapa-D, 2 especímenes (fig. 2f) .

a) Parte trasera de la cabeza plana.

b) Frente baja.

c) Sin barbilla.

d) Nariz grande y bulbosa.

Fase: Guanacaste.

Comp: Desconocida.

I-Chiapa-E, 2 especímenes (fig. $2 g$ ) .

a) Cabeza redonda y gorda, perfil en forma triangular.

b) Las cuencas del ojo punteadas en un lado de la nariz.

c) La boca es una mera cicatriz abierta.

Fase: Dili.

Comp: Desconocida.

J-Chiapa-F, 3 especímenes (fig. $2 h$ ).

a) Forma facial más o menos rectangular.

b) Cabeza plana tanto por delante como por detrás.

c) Frente que tiende a inclinarse hacia adelante.

Fase: Probablemente Dili.

Comp: Desconocida.

I-Chiapa-G, 3 especímenes (fig. 2i) .

a) Forma facial ovalada.

b) Nariz grande pero baja.

c) Boca abierta y a menudo con las comisuras hacia abajo. 
Fase: Francesa.

Comp: Desconocida.

l-(ihiapa- $H, 4$ especímenes (fig. $2 j$ ).

a) Cara redonda.

b) Ojos doblemente punteados.

c) Fleco alrededor de la cabeza que aumenta la redondez facial.

d) Barbilla muy desarrollada.

Fase: Francesa-Horcones.

Comp: Desconocida.

II-Chiapa- $A$, 7 especímenes (fig. 2k).

a) Figura altamente estilizada y deslumbrante.

b) Forma facial rectangular, con rasgos apresuradamente hechos.

c) Todos los rasgos faciales y la decoración están hechos con delgadísimas tiras de barro (pastillaje).

d) Tapones comunes para la nariz.

e) Ojo en forma de grano de café.

Fase: Istmo-Jiquipilas.

Comp: Las figurillas-silbatos de Acacoyagua (Drucker 1948, 159, 61, fig. 7, 8), muestran cierta semejanza, con su cara plana y triangular, con ojos oblicuos en forma de grano de café y con cuerpos mas bien toscos. Sin embargo ninguna de las figurillas de Chiapa de Corzo es silbato.

II-Chiapa- $A 1,3$ especímenes (fig. $2 l$ ).

a) Cara plana.

b) Ojo en forma de grano de café.

c) Rasgos faciales acentuados por marcas punteadas.

d) Orejas que son extensión de las mejillas, en forma tubular plana.

Fase: Istmo.

Comp: Iguales que las de II-Chiapa-A. 


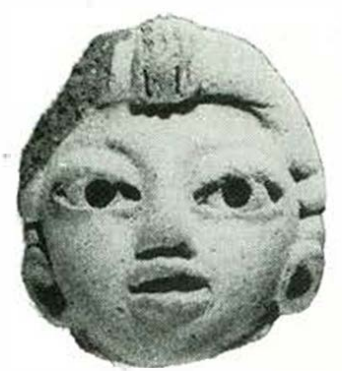

0
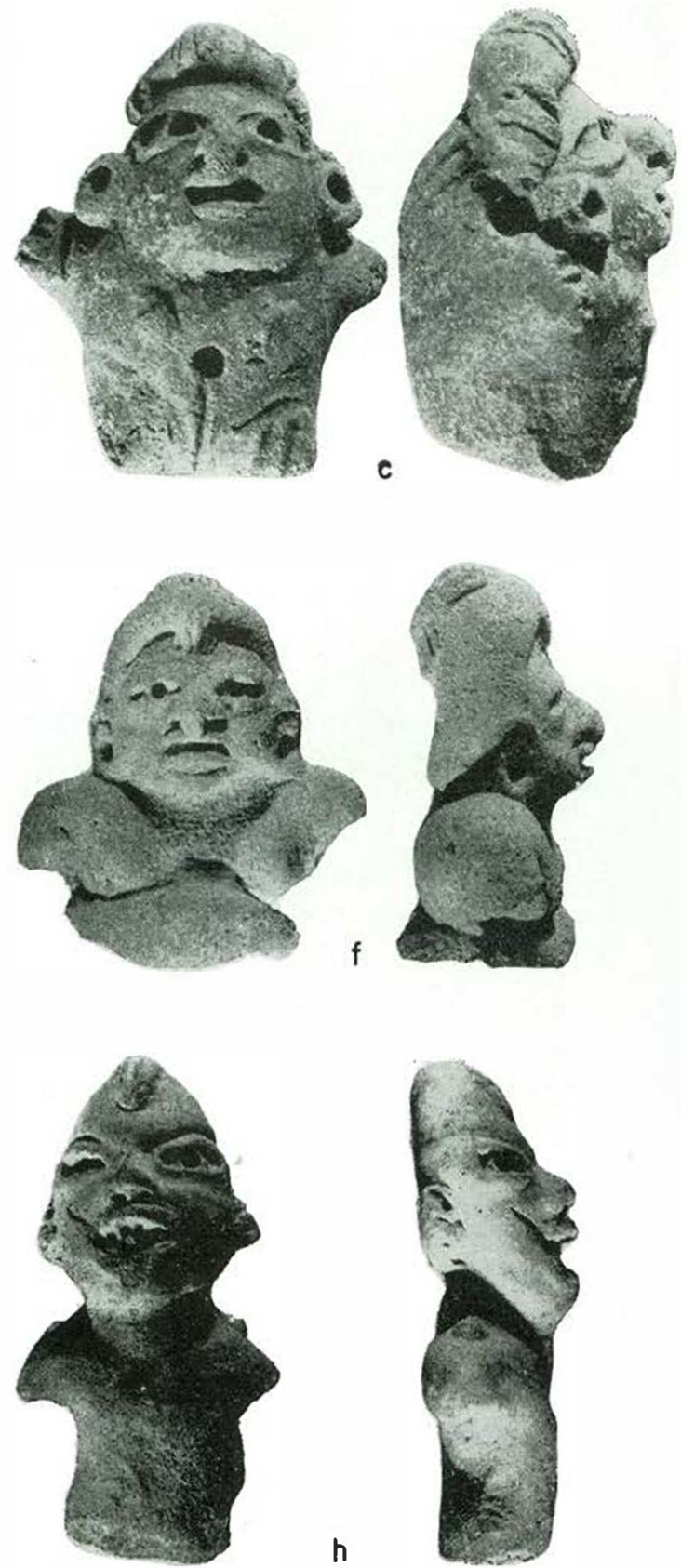

h
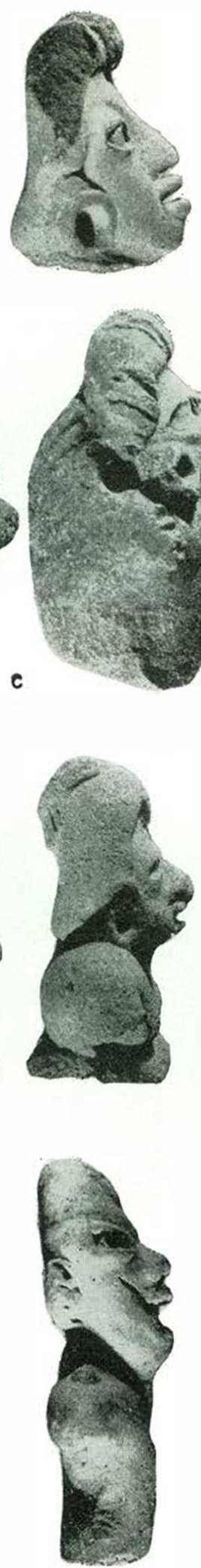

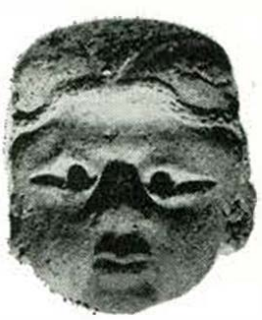

b
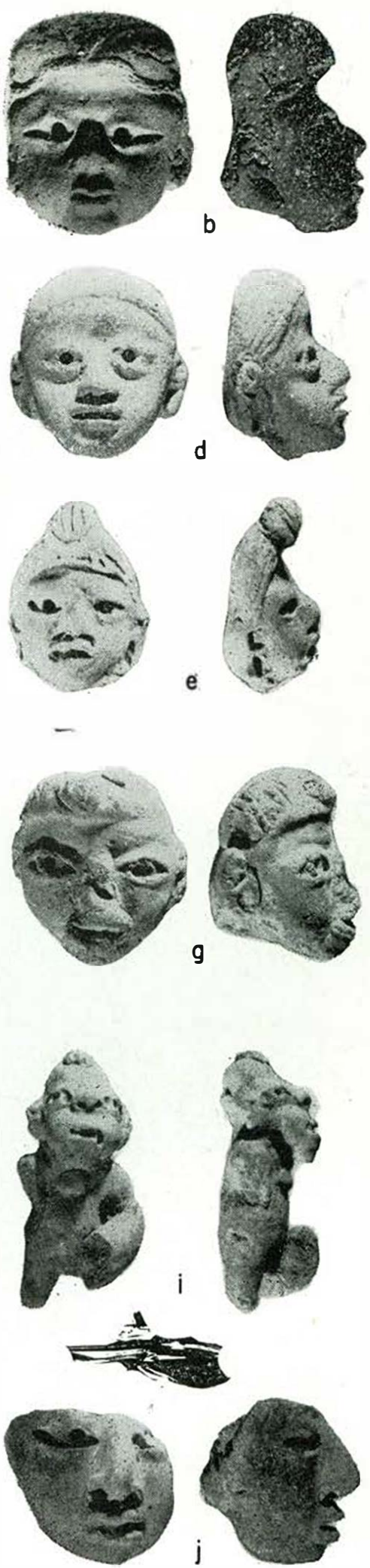

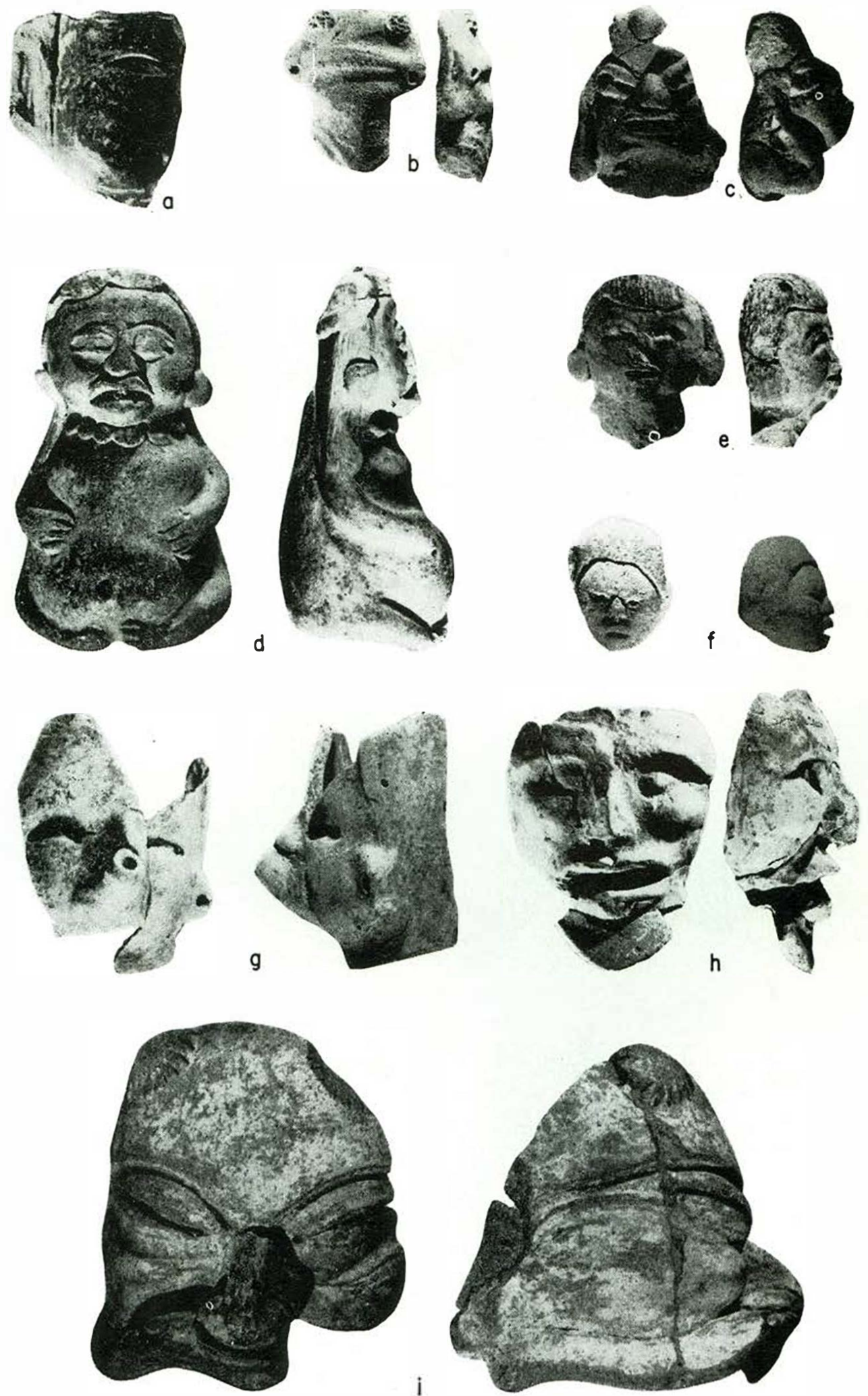

Estudios de Cultura Maya. Vol. VI, 1967

Fig. 3

Facultad de Filosofía y Letras, UNAM

https://revistas-filologicas.unam.mx/estudios-cultura-maya/ 

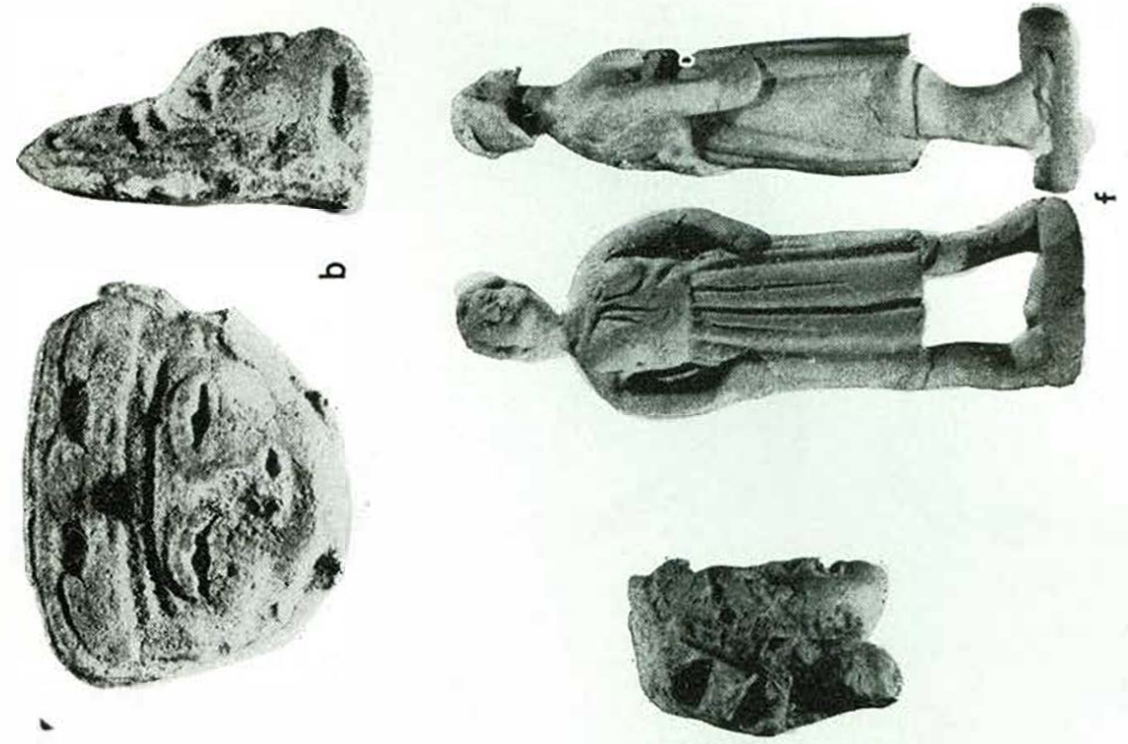

$\frac{5}{2}$

$\checkmark$
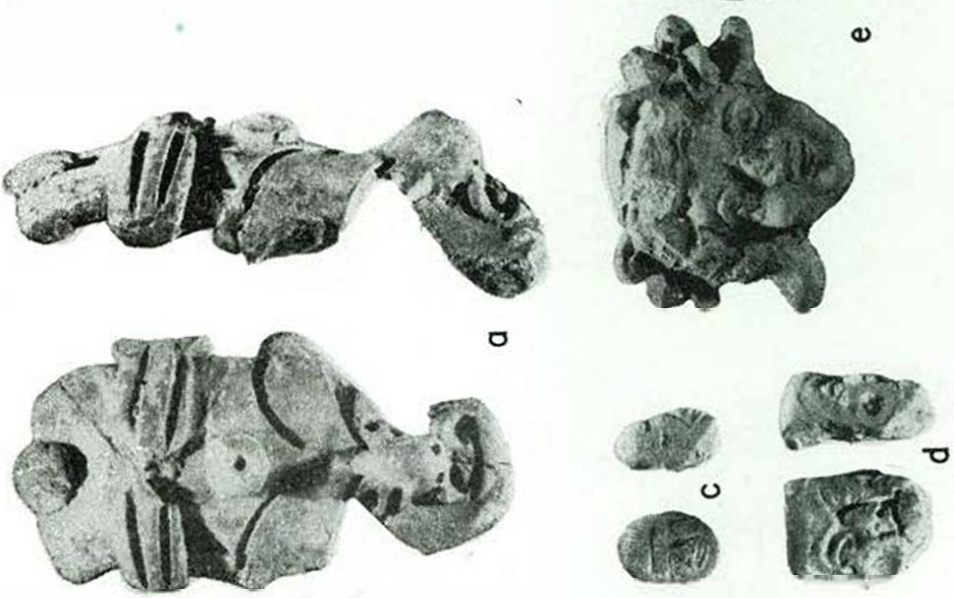

Estudios de Cultura Maya. Vol. VI, 1967

Facultad de Filosofía y Letras, UNAM

https://revistas-filologicas.unam.mx/estudios-cultura-maya/ 
II-Chiapa-B, 11 especímenes (fig. $2 n$ ).

a) Enorme nariz protuberante.

b) Ojos como ranuras rectangulares.

c) Parte trasera de la cabeza plana.

Fase: Francesa-Horcones.

Comp: Desconocida.

II-Chiapa-C, 8 especímenes (fig. 2o).

a) Ojo en forma de grano de café modificado.

b) Puente de la nariz muy levantado.

c) Falta de relieve natural en la cara.

Fase: Desconocida.

Comp: Desconocida.

II-Chiapa-A2, 6 especímenes (fig. $2 m$ ) .

a) Cabeza en forma de tubo ahuecado, rectangular.

b) Ranura del ojo larga y estrecha, muy inclinada hacia adentro.

c) Vestigios muy estilizados de orejas.

Fase: Istmo-Jiquipilas (?)

Comp: Desconocida.

II-Chiapa-D, 17 especímenes (fig. 3a).

a) Grandes cabezas tubulares y ahuecadas.

b) Pequeñas aplicaciones de tiras delgadas para los rasgos faciales.

c) Muy poco relieve facial.

Fase: Francesa-Guanacaste.

Comp: Desconocida.

II-Chiapa-E, 3 especímenes (fig. $3 b$ ).

a) No hay rasgos faciales, cara lisa, vacía.

b) Decoración de pastillaje punteado en la cabeza, o hileras punteadas representando el pelo. 
Fase: Desconocida.

Comp: Desconocida.

II-Chiapa-F, 2 especímenes (fig. 3c).

a) Cabeza redonda y gruesa, hueca o maciza.

b) Ojos punteados, con anchos cortes opuestos en forma de cuñas.

Fase: Desconocida.

Comp: Desconocida.

III-Chiapa- $A$, 28 especímenes (fig. 3d) .

a) Mejillas gruesas, labios hinchados o volteados hacia afuera; boca con comisuras hacia abajo.

b) Perfil entre moderado y excesivo prognatismo.

c) Cejas y nariz bajos y pesados.

d) Dos incisivos superiores protuberantes; muy característicos.

e) Tercera abertura profunda, a menudo entre las fosas nasales o encima del labio superior.

Fase: Francesa-Guanacaste.

Comp: No hay correlación directa con un tipo específico de figurilla. Ciertas características faciales similares con las figurillas de cerámica y jade de Tres Zapotes (Weiant 1943) y las figurillas de jade de La Venta (Drucker, Heizer y Squire, 1959).

III-Chiapa-A1, 5 especímenes (fig. $3 e$ ).

a) Cara ovalada.

b) Boca abierta, pero sin incisivos salientes.

c) Ojo, boca y fosas nasales hondamente modelados.

Fase: Istmo-Jiquipilas.

Comp: Desconocida.

III-Chiapa-B, 2 especímenes (fig. $3 g$ ).

a) Forma facial ovalada, rasgos delicadamente hechos.

b) Ojos estrechos, tocando hacia adentro la nariz en su parte media. 
c) El pelo bajo, en forma de capucha enmarca la cara; no está elaborado.

Fase: Desconocida.

Comp: Desconocida.

III-Chiapa-C, 2 especímenes (fig. 3f) .

a) Cabeza hueca, algo larga y tubular.

b) Perfil que muestra un prognatismo labial exagerado.

c) Mejillas gruesas que dan lugar a una boca fruncida tubular volteada hacia arriba.

Fase: Desconocida.

Comp: Deconocida.

III-Chiapa-D, 3 especímenes (fig. 3h).

a) Cabeza hueca.

b) Forma facial triangular, nariz muy puntiaguda.

c) Ojos: las cuencas modeladas y los globos de los ojos planos.

Fase: Desconocida.

Comp: Deconocida.

III-Chiapa-E, 6 especímenes (fig. 3i) .

a) La fragmentación de los especímenes quizás haya aumentado su heterogeneidad.

b) Grandes cabezas huecas.

c) Boca abierta, ojos en ranura o en cuencas modeladas.

Fase: Desconocida.

Comp: Deconocida.

III-Chiapa- $F, 5$ especímenes (fig. $4 a$ ).

a) Cabeza larga, estrecha y delgada, con elaborado tocado.

b) Pupilas punteadas en las cuencas delineadas en grabado.

c) Carece de relieve facial con excepción de una gran nariz.

Fase: Horcones.

Comp: Deconocida. 
IV-Chiapa- $A$, 3 especímenes (fig. 4b) .

a) Forma facial algo rectangular.

b) Plana la parte trasera de la cabeza.

c) Algo de prognatismo.

Fase: Istmo-Jiquipilas.

Comp: Deconocida.

IV-Chiapa-B, 2 especímenes (fig. $4 c-d$ ).

a) Cabezas en miniatura, poca similitud estilística.

b) Gran detalle facial.

Fase: Desconocida.

Comp: Pequeñas cabezas similares proceden de Tres Zapotes (Drucker 1943: 132, Pl. 42 f, g, n).

IV-Chiapa-C, 2 especímenes (fig. 4e) .

a) Cabeza redondeada con rasgos muy bien proporcionados.

b) Frente baja rematada con un elaborado peinado.

c) Hueca la parte trasera de la cabeza.

Fase: Inmediatamente después de la Conquista, probablemente. Comp: Desconocida.

IV-Chiapa-D, 4 especímenes (fig. 4f) .

a) Figuras femeninas con rasgos faciales de la Europa Occidental.

b) Vestido del Occidente Europeo.

c) Frente y espalda hechos separadamente y pegados después.

Fase: Moderna.

Comp: Típicas figurillas femeninas usadas en escenas navideñas en todo México.

\section{Cuerpos}

Los 243 cuerpos de las figurillas sin cabeza de Chiapa de Corzo son muy sencillos y sin ninguna elaboración, y no tienen, 
con excepción de dos ejemplos, ninguna relación con la tipología de las cabezas. No se dará aquí una descripción por cada tipo de cuerpos; haré solamente un comentario sobre las tres categorías generales de las características de los cuerpos de la colección, vista en conjunto.

Los cuerpos aparecen solamente como sentados o de pie, y aunque el porcentaje actual varía de un tipo a otro durante el periodo Preclásico y el Protoclásico, la posición sentada sobrepasa a la de pie cuatro o cinco veces. Es interesante notar que las figurillas no aparecen en acción o en posiciones poco dignas. La actitud modelo que la posición del cuerpo expresa, es la de una tranquila dignidad y cierta lejanía. En los periodos posteriores, la evidencia es menos definida, pero en general concuerda con lo dicho anteriormente, con quizás un mayor porcentaje de figurillas de pie.

Los cuerpos generalmente no están vestidos; cuando menos son raras las indicaciones de ropa, ya sea aplicada o incisa. Probablemente las figurillas tenían ropa pintada o llevaban trajes hechos de telas asequibles a los artistas. Hay, por supuesto, alguna prueba de lo primero, pero no de lo segundo. La evidencia en la ropa masculina está limitada a un número no mayor de diez ejemplos de calzones aplicados, un par corto y sin decoración y un cinturón; dos figurillas que se supone masculinas, llevan una blusa suelta en forma de túnica amarrada debajo del brazo con botones aplicados. Las figurillas femeninas llevan solamente falda con un dobladillo liso o decorado. Dos figurillas, probablemente femeninas, llevan sencillas blusas de manga corta; otra figurilla con blusa, tiene además un estrecho collar y unas grandes borlas que le cuelgan en la parte de enfrente.

Las características sexuales pueden ocurrir en las figurillas de Chiapa de Corzo, pero son muy raras. Hay solamente unas cuatro o cinco figurillas masculinas que tienen los genitales representados y unas pocas más figurillas femeninas. Los senos femeninos aparecen más a menudo, pero no bien desarrollados. La figurilla modelo es neutral, carece de características sexuales o éstas están ligeramente expresadas.

\section{LA FU.NCIÓN DE. LA FIGURILLA}

Antes de terminar estas consideraciones sobre las figurillas 
antropomorfas de Chiapa de Corzo, quisiera traer a la mente algunas de las posibles funciones de las figurillas, con la esperanza de que alguien aporte nuevas ideas sobre ello.

Podemos organizar algunas de estas funciones sobre la base de categorías culturales. Probablemente una de las funciones más a menudo representada por las figurillas, corresponde al término Religión. Por todo Mesoamérica se conocen las figurillas como idolos, reconocimiento local de la opinión general entre los no profesionales, sobre su función en el pasado. Generalmente se ha pensado que estos objetos eran adorados, ya fuera en oraciones o en ofrendas materiales como dioses personificados. Sabemos que entre los Itzá (Thompson 1951: 392-3) en el tiempo de la conquista, había numerosos idolitos en los templos, así como también en los hogares: dos o tres dioses caseros sentados en pequeñas bancas. Ninguno de los ídolos de los Itzá, sin embargo, parece haber sido hecho de barro. Los Itzá decían que los ídolos les hablaban frecuentemente y bailaban con ellos en las danzas de sacrificio. Sobre esto puede uno preguntarse si las figurillas en los bailes de sacrificio no son ina supervivencia del tiempo en que ellas, en vez de los seres humanos, eran sacrificadas. Quizás el rito del sacrificio humano nació de una primitiva costumbre de destrucción ceremonial de las figurillas de cerámica. Ciertamente se encuentran figuriIlas en gran abundancia durante la fase media y última del Preclásico $\mathrm{y}$, por lo menos en el sur de Mesoamérica, raramente cnteras o completas. Starr (1900: 83) registra el uso de figurillas hechas de madera, tela, barro y metal en las ceremonias de sacrificio de los otomíes y huastecos, cerca de San Pablo el Grande, municipio de Tenango. Las ceremonias se celebraban durante interminables fiestas, a la orilla de los lagos cerca de San Pablo, en donde los sacrificios se hacían en el propio lago para aplacar a la diosa femenina del agua que en él vivía. Todas las ceremonias tienen relación con la regularidad de las llu. vias, no excesiva, no insuficiente, para asegurar una buena cosecha.

Una hipótesis mágico-religiosa que siempre se invoca en relación con las figurillas es, por supuesto, que se usaban para el culto de la fertilidad, y se hallan muy íntimamente vincu. ladas a las ceremonias para aumentar la productividad, ya sea del grupo mismo, o de las plantas cultivadas o silvestres y de los animales. Las figurillas se usaban en el Valle de México 
atadas en cuerdas que se colocaban tirantes sobre los campos de maíz (Durán 1867, 1880: 274; Nuttall 1886: 328; Wardle 1905: 213-16) . No aparece claro cuál era su función; probablemente representar la petición hecha a alguna deidad en particular para que protegiera la milpa. Las figurillas, amarradas en tal forma a la cuerda tirante sobre la milpa, y moviéndose a la más leve brisa, pueden haber tenido una función muy príctica, como la de espantar a pájaros y animales en forma parecida a los modernos espantapájaros. Salta a la vista que, por lo menos en Chiapa de Corzo, los rasgos sexuales no se destacan, lo que implica que la hipótesis sobre el culto a la fertilidad, no parece ser una muy buena explicación para su función.

No se puede evitar el relacionar estas figurillas con la cosmología de una tribu, cuando se encuentran integrando la ofrenda mortuoria. Esta ocurrencia tiene amplia distribución en Mesoamérica y es indiscutible. En Chiapa de Corzo, sin embargo, solamente se han encontrado dos figurillas en entierros, lo que sugiere que aquí, por lo menos, las figurillas no formaban parte del concepto mortuorio. No he hecho todavía una detallada distribución, pero podría parecer que las figurillas enterradas con el difunto es una cc itumbre más bien norteña que sureña en Mesoamérica.

La Salud es la segunda categoría básica de la cultura respecto de la cual diversas hipótesis pueden establecerse sobre la función de las figurillas.

El uso de muñecas o pequeñas figuras humanas en ceremonias de curación, tiene una distribución etnográfica mundial, muy amplia y probablemente tuvo una similar en el pasado. Es de interés aquí la observación que hace Reichel-Dolmatoff sobre la enorme cantidad de muñecas esparcidas en las casas indígenas de ciertas tribus de Colombia (Evans y Meggers 1958: 181-2). Usadas las muñecas en ceremonias de curación, inmediatamente después de la ceremonia las consideraban seculares y no las trataban con el mismo respeto que antes. Una antigua práctica similar podría explicar muy bien la ocurrencia numerosa aunque casual de figurillas en Chiapa de Corzo.

Probablemente la interpretación más romántica sobre la función de la figurilla es su uso en malévolas ceremonias, las que conducian a enfermedades y hasta a la misma muerte. Este uso también tiene una vastísima distribución mundial, pero no ha sido ampliamente propuesto por los arqueólogos, quizá por la 
forma en que ha sido excesivamente popularizado por los no profesionales. Sin embargo, el número de figurillas usadas para este propósito está generalmente limitado entre cualquier grupo y generalmente se ocultan antes y después de utilizarse. La clevada densidad y su ocurrencia en depósitos que se hallan en plazas abiertas, tiende a negar esta hipótesis en Chiapa de Corzo.

Me gustaría sugerir también una hipótesis relativa a la Educación, en términos de una tercera categoría cultural. No es del todo inconcebible que las figurillas sirvieran antiguamente como las muñecas Kachina hoy en el proceso de enculturación entre los Hopi del sudoeste de los Estados Unidos. Las muñecas Kachina se usan para enseñar a los niños Hopi las cualidades, así como las características físicas de los diversos espíritus del panteón Hopi (Whiting 1964: 4). Esto puede ser parte de la función de las figurillas en la antigua Mesoamérica. Está ampliamente reconocido que el culto a Kachina y las ce. remonias de los bailes de enmascarados de todo el sudoeste de los Estados Unidos, están relacionados con los del norte de México y en última instancia con Mesoamérica; he aquí que la actual función de la muneca Kachina muy bien puede ser similar a la de las figurillas prehistóricas de la última área. El problema principal con esta hipótesis deriva de la falta de variedad de figurillas para compararlas con las del antiguo panteón religioso mesoamericano.

La enorme extensión y la variada topografía del área cultural mesoamericana, ha permitido el desarrollo de una considerable variedad cultural dentro de dicha área. Por lo tanto, es quizás un error buscar una función general de las figurillas sin especificar qué subárea y qué periodo se está tomando en consideración. Las figurillas probablemente tuvieron funciones diversas a través de toda la historia de Mesoamérica, según la subárea y el periodo a que corresponde. 